\title{
射影型反復学習による連続時間閉ループ同定法
}

\author{
酒 井 史 敏*・杉 江 俊 治**
}

\section{Continuous-time Closed-loop Identification Method via Projection Type Iterative Learning}

\author{
Fumitoshi SAKAI* and Toshiharu SUGIE**
}

\begin{abstract}
This paper presents a new framework for closed-loop identification of linear continuous-time systems directly from the sampled I/O data based on trial iterations. The method achieves identification through ILC (iterative learning control) concepts without any knowledge of compensators in the loop. The robustness against measurement noise is achieved through both projection of continuous-time I/O signals onto a finite dimensional space and noise tolerant learning algorithms. Its effectiveness is demonstrated through numerical examples for a linear, non-minimum phase and unstable plant.
\end{abstract}

Key Words: closed-loop identification, continuous-time system, projection type iterative learning

\section{1.はじめに}

フィードバック制御されている制御対象の入出力特性を同 定する, 閉ループ同定は, 古くから現場でのニーズの高い問題 としてさまざまなアプローチが研究されている1) 5). 特に, 制御対象が不安定系の場合にはフィードバックループを切断 した状態でデー夕を取得することが本質的に困難であり，安 定化制御器によりフィードバック制御系を構成して制御対象 の同定を行ないたい場合などで重要な役割を果たす.

閉ループ同定法を含めたシステム同定理論のほとんどが離 散時間上の入出力データに基づき離散時間モデルを同定して いるが, 連続時間システムは時定数など物理パラメータとの 対応が明確で解析が行ない易く, 種々のサンプリング時間に 応じた離散時間モデルを得ることができるという利点があり, 連続時間モデルを直接同定する方法が提案されている ${ }^{6) ~ 9)}$. しかし, 閉ループ系から連続時間モデルを直接同定する手法 はほとんど見あたらない。

著者らは，これまでに入力空間の有限次元化による反復学 習制御を利用した連続時間システム同定法を提案し, サンプ ルされた入出力信号から連続時間システムのパラメータが推 定されることを示し，過去の試行における情報を有効に利用 した耐雑音性を有する反復学習制御を提案している ${ }^{10) ~ 12) . ~}$ 一方で, 反復学習制御をフィードバック制御された制御系に

* 奈良工業高等専門学校 大和郡山市矢田町 22

** 京都大学大学院情報学研究科 宇治市五ヶ庄

* Nara National College of Technology, 22 Yata-cho, Yamatokoriyama

** Graduate School of Informatics, Kyoto University, Gokasho, Uji

(Received March 29, 2007)

(Revised August 7, 2007)

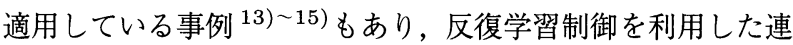
続時間システム同定法を閉ループ系に適用することができれ ば制御対象の連続時間モデルを直接同定することが可能にな ると考えられる。

そこで，本論文では著者らの提案した反復学習制御を利用 した連続時間システム同定法に基づき，フィードバック制御 により安定化された制御系から制御対象の連続時間モデルを 直接同定する手法を提案する。 また，学習更新則および学習 ゲインの選択に関しては著者らがこれまでに提案してきた手 法をそのまま適用することができ，開ループ系同定と閉ルー プ系同定を全く同様の枠組みで扱うことができることを示す. 提案手法の有効性は，モデル化誤差をもつ不安定かつ非最小 位相系に対して連続時間閉ループ同定を行なった数值例によ り示す.

本論文で用いる記号はつぎのとおりである．試行の反復回 数を上付文字で, 集合やべクトルの要素を下付文字で表わす. たとえば第 $k$ 試行目の入力 $u$ は $u^{k}$, ベクトル $\boldsymbol{\alpha}$ の第 $i$ 番目 の要素は $\boldsymbol{\alpha}_{i}$ と表わす.

\section{2. 問 題 設 定}

つぎの微分方程式によって表現される 1 入力 1 出力システ ムを制御対象とする。

$$
\begin{aligned}
y(t) & =\frac{B^{\circ}(p)}{A^{\circ}(p)} u(t) \\
& \triangleq \frac{\beta_{0}^{\circ}+\beta_{1}^{\circ} p+\cdots+\beta_{m}^{\circ} p^{m}}{\alpha_{0}^{\circ}+\alpha_{1}^{\circ}+\cdots+\alpha_{n-1}^{\circ} p^{n-1}+p^{n}} u(t)
\end{aligned}
$$

ここで, $u(t) \in L_{2}[0, T], y(t) \in L_{2}[0, T]$ はそれぞれ入 力と出力であり, $\alpha_{i}^{\circ} \in \mathbb{R}(i=0,1, \ldots, n-1), \beta_{i}^{\circ} \in \mathbb{R}$ $(i=0,1, \ldots, m)$ は分母.分子の係数である. また, $p$ は微 分オペレータであり，例えば $p u(t)=\mathrm{d} u(t) / \mathrm{d} t$ を意味する. 


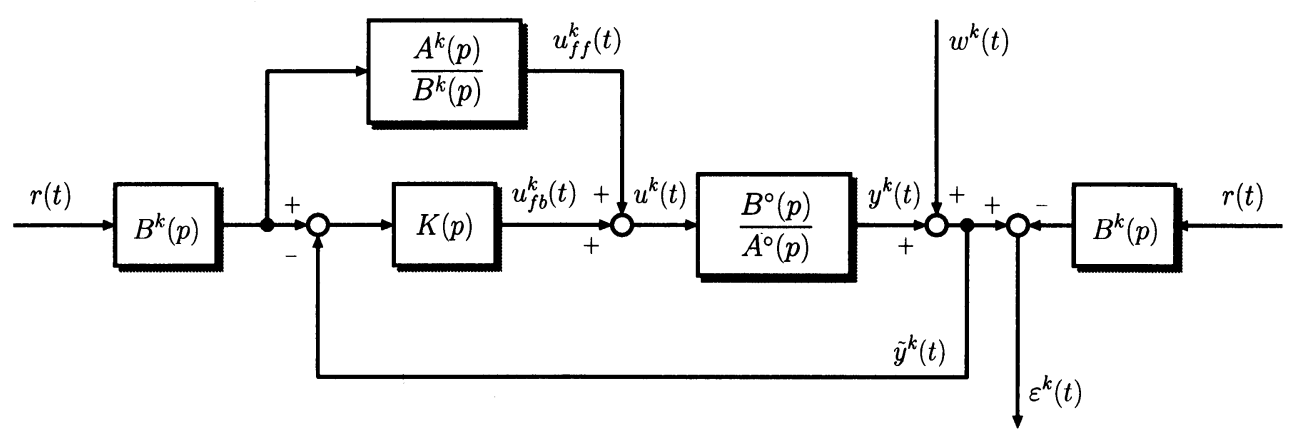

Fig. 1 Data generation scheme

ここで,

・制御対象は適当なコントローラ $K(p)$ によって安定化さ れている。

- 1 回の試行は有限時間区間 $[0, T]$ で行なわれ，それぞれ の試行はフィードバック制御系の平衡状態から開始される ものとする.

- 制御対象の分母多項式 $A^{\circ}(p)$ と分子多項式 $B^{\circ}(p)$ は既 約である. また, それぞれの次数 $n, m$ は既知であり, プ ロパ $(n \geq m)$ である.

・観測出力信号 $\tilde{y}(t)$ は正規性白色雑音 $w(t)$ が付加された 信号であり,

$$
\tilde{y}(t)=y(t)+w(t)
$$

で表わされる。

を仮定し，つぎの問題を考える.

連続時間閉ループ同定問題 : 観測出力信号 $\tilde{y}(t)$ および入 力信号 $u(t)$ に基づき制御対象の分母 - 分子の係数 $\alpha_{i}^{\circ} \in \mathbb{R}$ $(i=0,1, \cdots, n-1), \beta_{i}^{\circ} \in \mathbb{R}(i=0,1, \cdots, m)$ を求めよ.

\section{3. 射影型反復学習による同定法}

ここでは, 射影型反復学習により閉ループ系から直接連続 時間システム同定を行うための基本的なアイデアを連続時間 信号を用いて述べる.

まず，少なくとも $n$ 回微分可能な滑らかな信号 $r(t) \in$ $L_{2}[0, T]$ を選び, Fig. 1 に示すように, 第 $k$ 試行目に推 定された分子多項式 $B^{k}(p)$ に通した信号 $B^{k}(p) r(t)$ に制御対 象の出力信号 $y^{k}(t)$ を追従させること $\left(\varepsilon^{k}(t) \rightarrow 0,(k \rightarrow \infty)\right)$ を考える.ここで, 第 $k$ 試行目に推定された分母・分子多項 式をそれぞれ

$$
\begin{aligned}
& A^{k}(p) \triangleq \alpha_{0}^{k}+\alpha_{1}^{k} p+\cdots+\alpha_{n-1}^{k} p^{n-1}+p^{n} \\
& B^{k}(p) \triangleq \beta_{0}^{k}+\beta_{1}^{k} p+\cdots+\beta_{m}^{k} p^{m}
\end{aligned}
$$

で定義している.

このとき，フィードフォワード入力信号 $u_{f f}^{k}(t)$ は

$$
u_{f f}^{k}(t)=A^{k}(p) r(t)
$$

で与えられ, 出力信号 $\tilde{y}^{k}(t)$ は

$$
\begin{aligned}
\tilde{y}^{k}(t)= & \frac{\frac{B^{\circ}(p)}{A^{\circ}(p)}\left(K(p)+\frac{A^{k}(p)}{B^{k}(p)}\right)}{1+\frac{B^{\circ}(p)}{A^{\circ}(p)} K(p)} B^{k}(p) r(t) \\
& +\frac{1}{1+\frac{B^{\circ}(p)}{A^{\circ}(p)} K(p)} w^{k}(t)
\end{aligned}
$$

で表わされる，よって，追従誤差信号 $\varepsilon^{k}(t)$ は

$$
\begin{aligned}
\varepsilon^{k}(t) \triangleq \tilde{y}^{k}(t)-B^{k}(p) r(t) & \\
=T(p) A^{k}(p) r(t)-S(p) B^{k}(p) r(t) & \\
& +S(p) w^{k}(t)
\end{aligned}
$$

によって得られる。ここで，

$$
T(p) \triangleq \frac{\frac{B^{\circ}(p)}{A^{\circ}(p)}}{1+\frac{B^{\circ}(p)}{A^{\circ}(p)} K(p)}, \quad S(p) \triangleq \frac{1}{1+\frac{B^{\circ}(p)}{A^{\circ}(p)} K(p)}
$$

を定義している.

つぎに $n+m+1$ 次元の基底関数 $f_{1}(t), \ldots, f_{n+m+1}(t) \in$ $L_{2}[0, T]$ を導入し, 誤差信号 $\varepsilon^{k}(t)$ の $n+m+1$ 次元部分空間

$$
\mathcal{F} \triangleq \operatorname{span}\left\{f_{1}(t), f_{2}(t), \cdots, f_{n+m+1}(t)\right\}
$$

上への射影を考える. $\varepsilon^{k}(t)$ の部分空間 $\mathcal{F}$ 上への射影を

$$
\left.\varepsilon^{k}(t)\right|_{\mathcal{F}}=\delta_{1}^{k} f_{1}(t)+\cdots+\delta_{n+m+1}^{k} f_{n+m+1}(t)
$$

として, $n+m+1$ 次元ベクトル $\delta^{k} \triangleq\left[\delta_{1}^{k}, \cdots, \delta_{n+m+1}^{k}\right]^{T}$ で 表現する.ここで, 基底関数 $f_{i}(t) \quad(i=1,2, \ldots, n+m+1)$ は

$$
\begin{aligned}
& \int_{0}^{T}\left(T(p) A^{k}(p)-S(p) B^{k}(p)\right) r(t) f_{i}(t) \mathrm{d} t \\
& =\int_{0}^{T} \frac{B^{\circ}(p) A^{k}(p)-A^{\circ}(p) B^{k}(p)}{A^{\circ}(p)+B^{\circ}(p) K(p)} r(t) f_{i}(t) \mathrm{d} t=0,
\end{aligned}
$$

$$
i=1,2, \ldots, n+m+1
$$

を満たすとき, $B^{\circ}(p) A^{k}(p)-A^{\circ}(p) B^{k}(p)=0$ となるもの を選ぶものとする。この条件は観測雑音がない場合の追従誤 差信号

$$
e^{k}(t) \triangleq \frac{B^{\circ}(p) A^{k}(p)-A^{\circ}(p) B^{k}(p)}{A^{\circ}(p)+B^{\circ}(p) K(p)} r(t)
$$


を部分空間 $\mathcal{F}$ 上へ射影したとき，これが 0 ならばもとの 信号 $e^{k}(t)$ そのものが 0 でなければならないことを意味 している.ところが信号 $e^{k}(t)$ は $n+m+1$ 個の推定パ ラメータに関して線形なので, 上記条件を満たす基底関数 $f_{i}(t) \quad(i=1,2, \ldots, n+m+1)$ を見つけることは容易であ る.たとえば, 後の数值例に示すように $r(t)$ とその高階微分 によって基底を構成すればよい.なお， $A^{\circ}(p)$ と $B^{\circ}(p)$ は既 約であるので, $B^{\circ}(p) A^{k}(p)-A^{\circ}(p) B^{k}(p)=0$ が成立する ことは, $A^{k}(p)=A^{\circ}(p), B^{k}(p)=B^{\circ}(p)$ を意味する.

さらに，真の制御対象および第 $k$ 試行目に推定されたシス テムの分母・分子の係数を用いたパラメータベクトル

$$
\begin{aligned}
\gamma^{\circ} & \triangleq\left[\alpha_{0}^{\circ}, \cdots, \alpha_{n-1}^{\circ}, \beta_{0}^{\circ}, \cdots, \beta_{m}^{\circ}\right]^{T} \\
\gamma^{k} & \triangleq\left[\alpha_{0}^{k}, \cdots, \alpha_{n-1}^{k}, \beta_{0}^{k}, \cdots, \beta_{m}^{k}\right]^{T}
\end{aligned}
$$

を定義する。この $n+m+1$ 次元のパラメータベクトルを 用いると,フィードバック制御により安定化された閉ループ 系は

$$
\boldsymbol{\delta}^{k}=M \boldsymbol{\gamma}^{k}+\overline{\boldsymbol{\delta}}
$$

によって表現される．ここで, $M \in \mathbb{R}^{(n+m+1) \times(n+m+1)}$ は 定数行列であり, $\overline{\boldsymbol{\delta}}$ は分母多項式 $A^{k}(p)$ の最高次数の係数 $(=1)$ に対応するオフセット項である. 観測雑音がない場合 $\left(w^{k}(t)=0\right)$ を考えると, $\boldsymbol{\delta}^{k}=0$ が成り立つとき $0=M \boldsymbol{\gamma}^{k}+\overline{\boldsymbol{\delta}}$ は, 基底関数 $f_{i}(t)$ の選び方に関する仮定から, 唯一解 $\gamma^{k}=\gamma^{\circ}$ をもつ. すなわち, $M$ は正則で $\bar{\delta}=-M \gamma^{\circ}$ が成り立つ. し たがって，(5) 式は

$$
\delta^{k}=M\left(\gamma^{k}-\gamma^{\circ}\right)
$$

と表わされ，観測雑音を考慮したときは

$$
\delta^{k}=M\left(\gamma^{k}-\gamma^{\circ}\right)+\nu^{k}
$$

となる。ここで, $\boldsymbol{\nu}^{k} \in \mathbb{R}^{n+m+1}$ は観測雑音に対する出力 $S(p) w^{k}(t)$ を部分空間 $\mathcal{F}$ 上に射影したべクトルを表わして いる.

以上の準備の下で, $\gamma^{k}$ を何らかの学習更新則により更新 し, 信号 $B^{k}(p) r(t)$ に制御対象の出力信号 $y^{k}(t)$ を追従させ ることができれば $\gamma^{k} \rightarrow \gamma^{\circ}$ が達成される.

\section{4. 学習更新則と学習ゲイン}

閉ループ系を (6) 式で記述することによって, 著者らがこ れまでに提案した学習更新則および学習ゲインをそのまま利 用することができる，本論文ではつぎの学習更新則を適用す る (Fig. 2).

$$
\gamma^{k+1}=\gamma^{k}+H^{k} \delta^{k}
$$

ここで, $H^{k} \in \mathbb{R}^{(n+m+1) \times(n+m+1)}$ は試行回数 $k$ に対して逐 次的に更新する学習ゲインである.

学習ゲイン $H^{k}$ に関して以下の結果が得られている ${ }^{12)}$.
[命題] 次式で与えられる学習ゲイン $H^{k}$ を学習更新則 (7) 式に適用する。

$$
H^{k}=-\frac{1}{k+1} M^{-1}
$$

このとき，

$$
E\left[\left(\gamma^{k}-\gamma^{\circ}\right)\left(\gamma^{k}-\gamma^{\circ}\right)^{T}\right] \rightarrow 0, \quad k \rightarrow \infty
$$

が達成される。

読者の便宜のため，付録に証明を与えておく．

(8) 式の学習ゲインは, 閉ループ系のパラメータ空間表 現行列 $M$ が推定できていればその他の事前情報は一切必 要ないという利点がある。また，実験などにより推定した 不確かさをもつ行列 $\hat{M}$ を用いた場合においても，任意の ベクトル $x \neq 0$ に対して $x^{T} \hat{M}^{-1} M x>0$ を満たせば $E\left[\left(\gamma^{k}-\gamma^{\circ}\right)\left(\gamma^{k}-\gamma^{\circ}\right)^{T}\right] \rightarrow 0, k \rightarrow \infty$ が成り立ち, 行列 $M$ の推定誤差に対してロバスト性を有することが示されてい $る^{12)}$.

なお, 初期推定誤差の共分散行列 $P^{0}$ および観測雑音の共 分散行列 $V$ の情報が利用できる場合には，つぎの Kalman フィルタに基づく学習ゲインを用いることでさらによい推定 結果を得ることもできる ${ }^{12)}$.

$$
\begin{aligned}
H^{k} & =-P^{k} M^{T}\left(M P^{k} M^{T}+V\right)^{-1} \\
P^{k+1} & =P^{k}-P^{k} M^{T}\left(M P^{k} M^{T}+V\right)^{-1} M P^{k}
\end{aligned}
$$

ここで,

$$
\begin{aligned}
& V \triangleq E\left[\boldsymbol{\nu}^{k}\left(\boldsymbol{\nu}^{k}\right)^{T}\right] \\
& P^{0} \triangleq E\left[\left(\boldsymbol{\gamma}^{0}-\boldsymbol{\gamma}^{\circ}\right)\left(\boldsymbol{\gamma}^{0}-\boldsymbol{\gamma}^{\circ}\right)^{T}\right]
\end{aligned}
$$

である。

\section{5. ディジタル実装と行列 $M$ の推定}

ここでは，ディジタル実装するための準備を行ない，制御 対象のパラメー夕空間表現である行列 $M$ の推定を考える.

第 3 節における条件を満足する基底関数 $f_{i}(t) \quad(i=$ $1,2, \ldots, n+m+1)$ をそれぞれサンプリング時間 $T_{s}$ でサ ンプルし，縦に並べた行列を

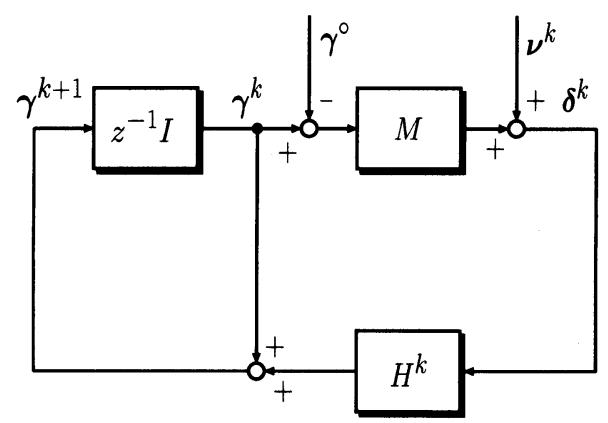

Fig. 2 Update law in parameter space 


$$
V_{d f} \triangleq\left[\begin{array}{cccc}
f_{1}(0) & f_{2}(0) & \ldots & f_{n+m+1}(0) \\
f_{1}\left(T_{s}\right) & f_{2}\left(T_{s}\right) & \ldots & f_{n+m+1}\left(T_{s}\right) \\
\vdots & \vdots & \ldots & \vdots \\
f_{1}\left(N T_{s}\right) & f_{2}\left(N T_{s}\right) & \ldots & f_{n+m+1}\left(N T_{s}\right)
\end{array}\right]
$$

と定義し，この行列 $V_{d f}$ を $\mathrm{QR}$ 分解により次式を満足する $U \triangleq\left[\boldsymbol{f}_{1}, \boldsymbol{f}_{2}, \ldots, \boldsymbol{f}_{n+m+1}\right] \in \mathbb{R}^{(N+1) \times(n+m+1)}$ と正則な上三 角行列 $R \in \mathbb{R}^{(n+m+1) \times(n+m+1)}$ との積により表わす.

$$
V_{d f}=U R, \quad U^{T} U=I_{n+m+1}
$$

さらに, $n$ 回微分可能な信号 $r(t)$ を選び, $V_{r}(t), \boldsymbol{\alpha}^{k}, \boldsymbol{\beta}^{k}$ を

$$
\begin{aligned}
V_{r}(t) & =\left[r(t), \frac{\mathrm{d} r(t)}{\mathrm{d} t}, \ldots, \frac{\mathrm{d}^{n} r(t)}{\mathrm{d} t^{n}}\right] \\
\boldsymbol{\alpha}^{k} & \triangleq\left[\alpha_{0}^{k}, \alpha_{1}^{k}, \ldots, \alpha_{n-1}, 1\right]^{T} \\
\boldsymbol{\beta}^{k} & \triangleq\left[\beta_{0}^{k}, \beta_{1}^{k}, \ldots, \beta_{m}^{k}\right]^{T}
\end{aligned}
$$

で定義する.このとき, $u_{f f}^{k}(t)=A^{k}(p) r(t)$ と $B^{k}(p) r(t)$ は

$$
\begin{aligned}
& A^{k}(p) r(t)=V_{r}(t) \boldsymbol{\alpha}^{k} \\
& B^{k}(p) r(t)=V_{r}(t)[1: m+1] \boldsymbol{\beta}^{k}
\end{aligned}
$$

と表わすことができる。ここで, $V_{r}(t)[1: m+1]$ は $V_{r}(t)$ の 1 から $m+1$ 列目によって構成されるベクトルを意味して いる.

サンプリング時間 $T_{s}$ でサンプルされた第 $k$ 試行目の入出 力信号をベクトル化して

$$
\begin{gathered}
\boldsymbol{u}_{f f}^{k} \triangleq\left[u_{f f}^{k}(0), u_{f f}^{k}\left(T_{s}\right), \cdots, u_{f f}^{k}\left(N T_{s}\right)\right]^{T} \in \mathbb{R}^{N+1} \\
\tilde{\boldsymbol{y}}^{k} \triangleq\left[\tilde{y}^{k}(0), \tilde{y}^{k}\left(T_{s}\right), \cdots, \tilde{y}^{k}\left(N T_{s}\right)\right]^{T} \in \mathbb{R}^{N+1}
\end{gathered}
$$

とする。同様に他の信号も $\boldsymbol{y}^{k} \in \mathbb{R}^{N+1}, \boldsymbol{\varepsilon}^{k} \in \mathbb{R}^{N+1}$, $\boldsymbol{w}^{k} \in \mathbb{R}^{N+1}$ と表わしておく. 時変べクトル $V_{r}(t)$ もサン プルし, $V_{d r} \in \mathbb{R}^{(N+1) \times(n+1) を}$

$$
V_{d r} \triangleq\left[\begin{array}{cccc}
r(0) & \dot{r}(0) & \ldots & r^{(n)}(0) \\
r\left(T_{s}\right) & \dot{r}\left(T_{s}\right) & \ldots & r^{(n)}\left(T_{s}\right) \\
\vdots & \vdots & \ldots & \vdots \\
r\left(N T_{s}\right) & \dot{r}\left(N T_{s}\right) & \ldots & r^{(n)}\left(N T_{s}\right)
\end{array}\right]
$$

と定義しておけば，第 $k$ 試行目におけるフィードフォワード 入力信号 $\boldsymbol{u}_{f f}^{k}$ は

$$
\boldsymbol{u}_{f f}^{k}=V_{d r} \boldsymbol{\alpha}^{k}
$$

と表わされる.

つぎに，定数行列 $M$ を推定することを考える（3) 式の $T(p)$ と $S(p)$ は 1 入力 1 出力線形時不変系であるから, 0 次 ホールドされた入力 $\boldsymbol{u}^{k}$ に対応する出力 $\boldsymbol{y}^{k}$ は試行回数 $k$ に 関係なくそれぞれ

$$
\boldsymbol{y}_{T}^{k}=G_{T} \boldsymbol{u}^{k}, \quad \boldsymbol{y}_{S}^{k}=G_{S} \boldsymbol{u}^{k}
$$

によって表わされる.ここで, $G_{T}, G_{S} \in \mathbb{R}^{(N+1) \times(N+1)}$ は

$$
\begin{gathered}
G_{T}=\left[\begin{array}{ccccc}
g_{T 0} & 0 & 0 & \ldots & 0 \\
g_{T 1} & g_{T 0} & 0 & \ldots & 0 \\
g_{T 2} & g_{T 1} & g_{T 0} & \ldots & 0 \\
\vdots & \vdots & \vdots & \ldots & \vdots \\
g_{T N} & g_{T N-1} & g_{T N-2} & \ldots & g_{T 0}
\end{array}\right] \\
G_{S}=\left[\begin{array}{ccccc}
g_{S 0} & 0 & 0 & \ldots & 0 \\
g_{S 1} & g_{S 0} & 0 & \ldots & 0 \\
g_{S 2} & g_{S 1} & g_{S 0} & \ldots & 0 \\
\vdots & \vdots & \vdots & \ldots & \vdots \\
g_{S N} & g_{S N-1} & g_{S N-2} & \ldots & g_{S 0}
\end{array}\right]
\end{gathered}
$$

である. $G_{T}, G_{S}$ の第 1 列目は，それぞれ $T(p), S(p)$ に $\boldsymbol{u}=[1,0,0, \cdots, 0]^{T}$ を入力したときの出力 $\boldsymbol{y}_{T}$ および $\boldsymbol{y}_{S}$ で ある。実験によって得られる行列 $G_{T}$ および $G_{S}$ を用いると， 誤差信号 $\varepsilon^{k}$ は

$$
\boldsymbol{\varepsilon}^{k}=G_{T} V_{d r} \boldsymbol{\alpha}^{k}-G_{S} V_{d r}[1: m+1] \boldsymbol{\beta}^{k}
$$

のように表わされる， $\boldsymbol{f}_{i}(i=1,2, \ldots, n+m+1)$ は正規直 交基底であるので，誤差信号 $\varepsilon^{k}$ の射影は

$$
\delta^{k}=U^{T} \varepsilon^{k}
$$

で表わされる。したがって，(5)式の $M$ と $\bar{\delta}^{k}$ は

$$
\begin{aligned}
M & =U^{T}\left[G_{T} V_{d r}[1: n],-G_{S} V_{d r}[1: m+1]\right] \\
\overline{\boldsymbol{\delta}} & =U^{T} G_{T} V_{d r}[n+1]
\end{aligned}
$$

となり，パラメータベクトルの初期推定值 $\gamma^{0}$ は

$$
\gamma^{0}=-M^{-1} \bar{\delta}
$$

によって求めることができる.

行列 $M$ を求めるためには安定化された閉ループ系の応答 のみが必要であり，コントローラ $K(p)$ の複雑さは影響しな いことに注意する。

\section{6. 数 值 例}

次式の伝達関数で表わされる非最小位相かつ不安定なシス テムを同定したい実システムと考える.

$$
P(s)=\frac{-0.5 s+1}{s^{3}+5 s^{2}+4 s-10}
$$

このシステムの正確なパラメータはわかっておらず，ノミナ ルモデルが

$$
\hat{P}(s)=\frac{-0.6 s+0.8}{s^{3}+6 s^{2}+5 s-8}
$$

で与えられるとする。 ノミナルモデルおよび実システムを安 定化するコントローラ $K(s)$ として，ノミナルモデルに基づ き $\mathcal{H}^{\infty}$ ループ整形法により設計したコントローラ

$$
K(s)=\frac{1193.6(s+4.489)(s+2.289)(s+0.000838)}{s(s+15.65)(s+7.43)\left(s^{2}+1.412 s+10.3\right)}
$$


を用いる。

つぎに，前述の議論に基づき，パラメー夕推定誤差が $\boldsymbol{\delta}^{k} \rightarrow$ $0, k \rightarrow \infty$ を達成するようなフィードフォワード入力 $u_{f f}(t)$ を加えることを考える. $n$ 回微分可能な信号 $r(t)$ をつぎの伝 達関数で記述されるフィルタに 11 のピーク值をもつ矩形波 信号を入力したときの出力信号として与え $V_{d r}$ を求める.

$$
F(s)=\frac{10^{5}}{(s+10)^{5}}
$$

また，基底関数も信号 $r(t)$ を用いて

$$
f_{1}(t)=r(t), f_{2}(t)=\frac{\mathrm{d} r(t)}{\mathrm{d} t}, \ldots, f_{5}(t)=\frac{\mathrm{d}^{4} r(t)}{\mathrm{d} t^{4}}
$$

と選び, $U=\left[f_{1}, f_{2}, \ldots, f_{5}\right]$ を求めておく.

制御対象およびコントローラに関して全く事前情報のない 場合は前章で述べたように実験により $G_{T}$ および $G_{S}$ を求め ればよいが，ここでは制御対象のノミナルモデル $\hat{P}(s)$ およ びコントローラ $K(s)$ の情報が利用できるとして，ノミナル モデルを用いた閉ループ系から $(12)$ 式の $G_{T}$ および $G_{S}$ を 求め,ノミナルモデルを用いた閉ループ系のパラメー夕空間 表現である行列 $\hat{M}$ および $\bar{\delta}$ をそれぞれ (13), (14) 式により 計算し，(15) 式により初期推定值 $\gamma^{0}$ を求める.

以上の準備のもとで, (7) 式の学習更新則に, (8) 式の学習 ゲインを用い, 50 回の試行を行なった結果を以下に示す.こ こで, 各試行における時間区間は $T=10[\mathrm{~s}]$ であり, サンプ リング時間は $T_{s}=10[\mathrm{~ms}]$ としている．すなわち， 1 試行に おけるデー夕数は 1001 である. 第 0 回目および第 10 回目の 試行における観測出力 $\tilde{y}^{k}(t)$ と信号 $B^{k}(p) r(t)$ を Fig. 3 に 示している（図中, 実線が信号 $B^{k}(p) r(t)$, 破線が観測出力 $\left.\tilde{y}^{k}(t)\right)$. ここで, 出力信号 $y^{k}(t)$ には雑音対信号比 (NSR) が およそ $10 \%$ となるように正規性白色雑音を加えている。試行 の繰り返しにより信号 $B^{k}(p) r(t)$ に観測出力 $\tilde{y}^{k}(t)$ が追従し ていることが確認できる. また, 各試行ごとに同定されたシ ステムのパラメータを Fig. 4 に示しているが，10 回程度の 試行でほほ正確にそれぞれのパラメータが実システムのパラ メー夕 $\left(\alpha_{0}=-10, \alpha_{1}=4, \alpha_{2}=5, \beta_{0}=1, \beta_{1}=-0.5\right)$ に収束しており，Fig. 5 に示すように各試行におけるパラ メータ推定誤差のユークリッドノルム $\left\|\gamma^{k}-\gamma^{\circ}\right\|$ は試行の 繰り返しによって指数的に減少していることが確認できる. Fig. 6 には 50 種類の異なる観測雑音を加えたときの同定結 果において, 第 10 回目の試行で同定されたシステムの Bode 線図を重ねてプロットしている。ここで，実線は真のシステ ム（(16) 式）を表わしているが, 観測雑音の影響をほとんど 受けず正確に真のシステムと一致する結果が得られた。

\section{7.おわりに}

本論文では, 射影型反復学習を利用しフィードバック制御 により安定化された制御系から制御対象の連続時間モデルを 直接同定する連続時間閉ループ同定法を提案した. また, 学 習更新則および学習ゲインの選択に関しては著者らがこれま

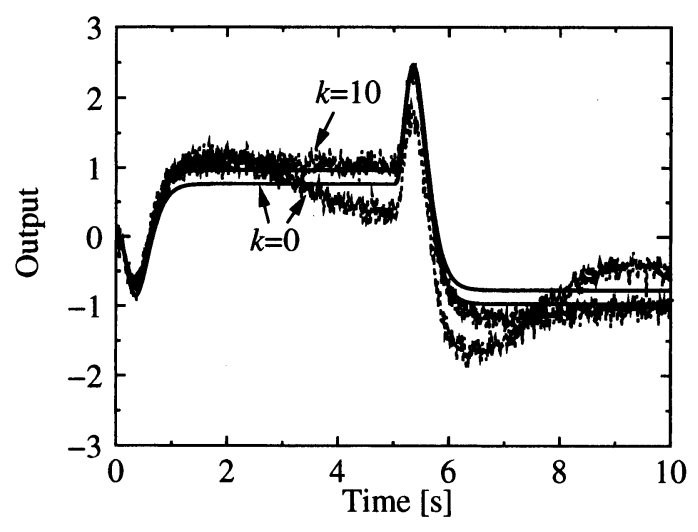

Fig. 3 Measured output $\tilde{y}^{k}(t)$ and $B^{k}(p) r(t)$

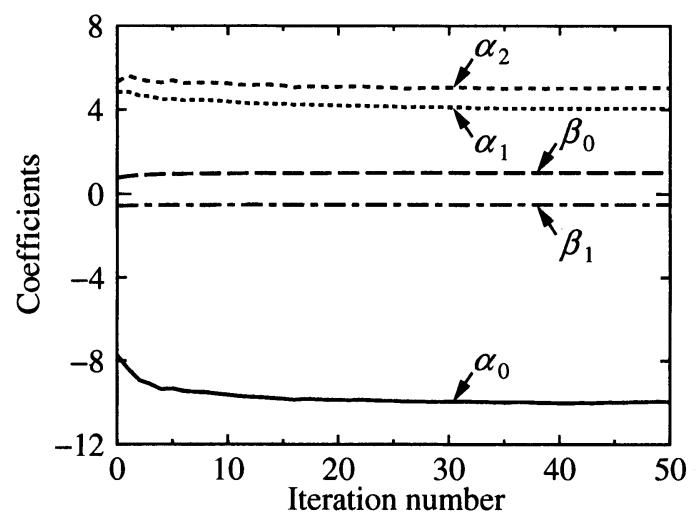

Fig. 4 Identified coefficients $\boldsymbol{\gamma}^{k}$ in each trial (True value: $\left.\alpha_{0}=-10, \alpha_{1}=4, \alpha_{2}=5, \beta_{0}=1, \beta_{1}=-0.5\right)$

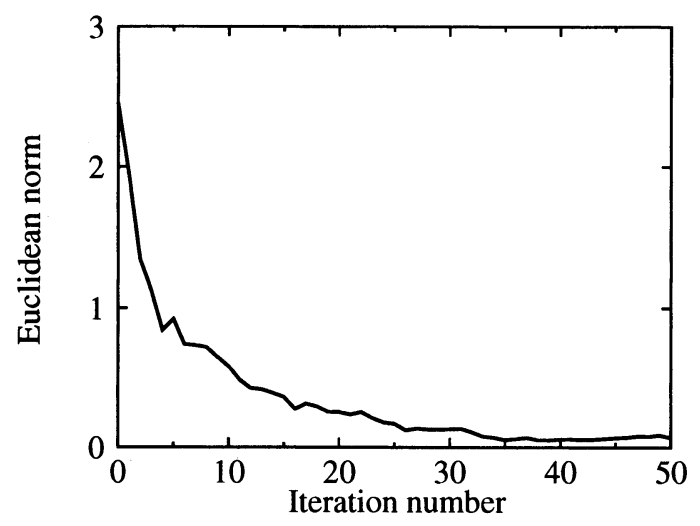

Fig. 5 Euclidean norm of the parameter estimation error $\left\|\boldsymbol{\gamma}^{k}-\boldsymbol{\gamma}^{\circ}\right\|$

でに提案してきた手法をそのまま適用することができ，開ルー プ系同定と閉ループ系同定を全く同様の枠組みで扱うことが できることを示した．最後に，モデル化誤差をもつ不安定か つ非最小位相系の連続時間閉ループ同定を行なった数值例を 示し, 提案法の有効性を示した. 今後の課題としては本結果 の多変数系やあるクラスの非線形系への拡張があげられる.

\section{参 考 文 献}

1) T. Söderström and P. Stoica: System identification, Englewood Cliffs, NJ: Printice-Hall (1989) 


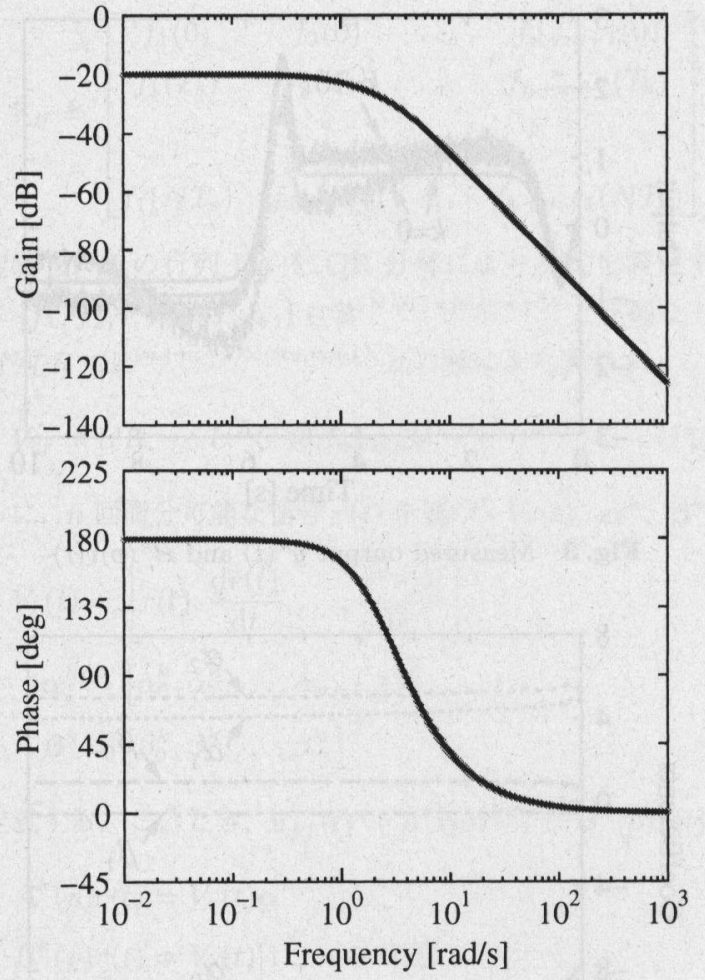

Fig. 6 Bode plots of the identified system $(k=10)$

2) L. Ljung: System Identification - Theory for the User; Second Edition, Englewood Cliffs, NJ: Printice-Hall (1999)

3) F.G. Hansen and G.F. Franklin: On a fractional representation approach to clesed-loop experiment design, Proc. of American Control Conference, 1319/1320 (1988)

4) M. Verhaegen: Application of a subspace model identification technique to identify LTI systems operating in closedloop, Automatica, 29-4, 1027/1040 (1993)

5) B. Codrons, B.D.O. Anderson and M. Gevers: Closed-loop identification with an unstable or nonminimum phase controller, Automatica, 38-12, 2127/2137 (2002)

6) P. Young: Parameter estimation for continuous-time models - a survey, Automatica, 17-1, 23/39 (1981)

7) H. Unbehauen and G.P. Rao: Continuous-time approaches to system identification - a survey, Automatica, 26-1, 23/35 (1990)

8) N.K. Sinha and G.P. Rao: Identification of ContinuousTime Systems, Kluwer Academic Publishers (1991)

9) H. Garnier and M. Mensler: The CONTSID toolbox: a Matlab toolbox for CONtinuous-Time System IDentification, Proc. of the 12th IFAC Symposium on System Identification (2000)

10）酒井，杉江：反復学習制御に基づく連続時間システム同定，計 測自動制御学会論文集，40-11, 1098/1104 (2004)

11）酒井, 杉江：連続時間システム同定のための耐雑音性を有する反 復学習制御, 計測自動制御学会論文集, 42-5, 543/550 (2006)

12) M.C. Campi, T. Sugie and F. Sakai: Iterative identification method for linear continuous-time systems, Proc. of the 45th IEEE Conference on Decision and Control, 817/822 (2006)

13) N. Amman, D.H. Owens, E. Rogers and A. Wahl: An $H_{\infty}$ approach to linear iterative learning control design, International Journal of Adaptive Control and Signal Processing, 10-6, 767/781 (1996)

14) R.W. Longman: Iterative learning control and repetitive control for engineering practice, International Journal of Control, 73-10, 930/954 (2000)

15) S. Gunnarsson and M. Norrlöf: On the design of ILC algorithms using optimization, Automatica, 37-12, 2011/2016 (2001)

《付 録》

A. 命題の証明

(7) 式に (6) 式を代入すると

$$
\gamma^{k+1}=\gamma^{k}+H^{k} M\left(\gamma^{k}-\gamma^{\circ}\right)+H^{k} \nu^{k}
$$

となり, $\tilde{\gamma}^{k} \triangleq \gamma^{k}-\gamma^{\circ}$ を定義すれば

$$
\tilde{\gamma}^{k+1}=\left(I+H^{k} M\right) \tilde{\gamma}^{k}+H^{k} \nu^{k}
$$

を得る.(8) 式の学習ゲインを適用すると

$$
\begin{aligned}
\tilde{\gamma}^{k+1} & =\left(I-\frac{1}{k+1} M^{-1} M\right) \tilde{\gamma}^{k}-\frac{1}{k+1} M^{-1} \nu^{k} \\
& =\frac{k}{k+1} \tilde{\gamma}^{k}-\frac{1}{k+1} M^{-1} \nu^{k}
\end{aligned}
$$

となるので, $V \triangleq E\left[\boldsymbol{\nu}^{k}\left(\boldsymbol{\nu}^{k}\right)^{T}\right]$ を定義すると

$$
\begin{aligned}
E & {\left[\tilde{\gamma}^{k+1}\left(\tilde{\gamma}^{k+1}\right)^{T}\right] } \\
& =\frac{k^{2}}{(k+1)^{2}} E\left[\tilde{\gamma}^{k}\left(\tilde{\gamma}^{k}\right)^{T}\right]+\frac{1}{(k+1)^{2}} M^{-1} V\left(M^{-1}\right)^{T} \\
& =\underbrace{\left[\frac{1}{(k+1)^{2}}+\cdots+\frac{1}{(k+1)^{2}}\right]}_{(k+1) \text {-times }} M^{-1} V\left(M^{-1}\right)^{T} \\
& =\frac{1}{k+1} M^{-1} V\left(M^{-1}\right)^{T}
\end{aligned}
$$

となるから,$k \rightarrow \infty$ のとき $E\left[\tilde{\gamma}^{k+1}\left(\tilde{\gamma}^{k+1}\right)^{T}\right] \rightarrow 0$.

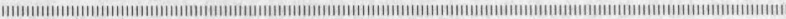

$$
\text { [著 者 紹 介] }
$$

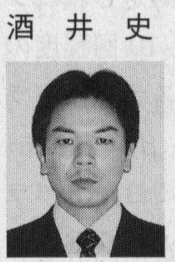

政正員)

2001 年金沢大学大学院自然科学研究科博士後期 課程修了. 同年奈良工業高等専門学校助手. 2007 年同助教. システム同定, メカトロニクスシステ ムの制御などの研究に従事. 博士 (工学). システ 么制御情報学会, 日本機械学会, IEEE の会員.

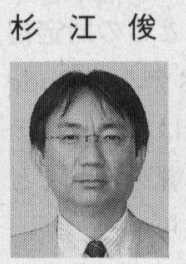

(正会員・フェロー)

1978 年京都大学大学院修士課程精密工学専攻 修了. 84 年同博士後期課程研究指導認定退学. 78 年 $~ 80$ 年日本電信電話公社勤務. 84 年大阪府立 大学工学部助手. 88 年京都大学工学部助教授を経 て, 現在情報学研究科教授. ロバスト制御, シス テム同定, 非線形制御などの研究に従事. 工学博 土. 91 年システム制御情報学会椹木記念論文賞. 98 年同論文賞. $94,2000,2003$ 年計測自動制御学 会論文賞を受賞. IEEE フェロー.システム制御 情報学会, 日本ロボット学会, IEEE などの会員. 